\title{
An Iron Uptake Operon Required for Proper Nodule Development in the Bradyrhizobium japonicum-Soybean Symbiosis
}

\author{
Heather P. Benson, Eric Boncompagni, and Mary Lou Guerinot \\ Department of Biological Sciences; 6044 Gilman, Dartmouth College, Hanover, NH 03755 U.S.A.
}

Submitted 10 January 2005. Accepted 22 April 2005.

\begin{abstract}
Rhizobia live in the soil or enter into a nitrogen-fixing symbiosis with a suitable host plant. Each environment presents different challenges with respect to iron acquisition. The soybean symbiont Bradyrhizobium japonicum 61A152 can utilize a variety of siderophores (Fe[III]-specific ligands). Purification of iron-regulated outer membrane proteins had previously allowed the cloning of a gene, $f e g A$, from $B$. japonicum 61A152, whose predicted protein shares significant amino acid similarity with known TonB-dependent siderophore receptors. Here, we show that $f e g A$ is in an operon with a gene, $f e g B$, that is predicted to encode an inner membrane protein. Characterization of $f e g A B$ and $f e g B$ mutants shows that both $f e g A$ and $f e g B$ are required for utilization of the siderophore ferrichrome. Whereas the $f e g B$ mutant forms a normal symbiosis, the $f e g A B$ mutant has a dramatic phenotype in planta. Six weeks after inoculation with a $f e g A B$ strain, soybean nodules do not contain leghemoglobin and do not fix nitrogen. Infected cells contain few symbiosomes and are filled with vesicles. As ferrichrome is a fungal siderophore not likely to be available in nodules, the symbiotic defect suggests that the $f e g A B$ operon is serving a different function in planta, possibly one involved in signaling between the two partners.
\end{abstract}

Additional keywords: nitrogen fixation.

Although iron is the fourth most abundant element in the earth's crust, iron is essentially unavailable in aerobic environments at biological $\mathrm{pH}$, as it tends to form insoluble $\mathrm{Fe}$ (III) oxyhydroxides (Guerinot and Yi 1994). In order to obtain this essential nutrient, rhizobia and other soil organisms must find a way to solubilize iron, as well as a way to compete with other iron-requiring organisms. Rhizobia face additional challenges when they enter into a nitrogen-fixing symbiosis. As endosymbionts, these bacteria must have mechanisms for acquiring iron from the host plant. They also have an increased need for iron as microsymbionts, producing three times as many cytochromes as when they are free-living (Sangwan and O'Brian 1992) and synthesizing nitrogenase (containing at least 30 iron atoms), which can be 10 to $12 \%$ of the total bacterial protein (Verma and Long 1983).

Current Address for Eric Boncompagni: UMR Interactions Plantes Microorganismes et Santé Végétale, INRA-UNSA-CNRS, 6192, 400 Routes des Chappes, 06903 Sophia Antipolis Cedex, France.

Corresponding author: Mary Lou Guerinot;

E-mail: guerinot@Dartmouth.edu
The soybean symbiont Bradyrhizobium japonicum 61A152 can utilize a variety of siderophores produced by other microorganisms as iron sources, facilitating its survival in the rhizosphere (Plessner et al. 1993). In order to utilize a particular siderophore, bradyrhizobia need specific uptake systems, usually composed of a high-affinity outer membrane receptor, the TonB energy-transducing complex, a periplasmic binding protein, and an inner membrane-associated ATP transporter system (Wandersman and Delepelaire 2004). These genes are often found in operons. For example, the Escherichia coli ferrichrome uptake system is encoded by the $f h u A C D B$ operon. The four Fhu proteins function in conjunction with TonB, ExbB, and ExbD to transport ferrichrome across both the inner and outer membranes. The genes encoding these iron uptake proteins are usually coordinately derepressed under conditions of iron deficiency and are negatively regulated by the fur gene (Andrews et al. 2003).

In order to determine the relative importance of siderophore utilization in symbiotic and soil environments, we decided to identify the genes encoding the iron-regulated outer membrane proteins (OMP) and to use a reverse genetic approach to determine which siderophores were transported into the cell via each receptor. The first gene identified by this approach was $f e g A$ (LeVier and Guerinot 1996). fegA encodes a protein with significant amino acid similarity to a number of known siderophore receptors, including the ferrichrome receptors from E. coli (Coulton et al. 1986) and Vibrio cholerae (Rogers et al. 2000) and the chrysobactin receptor from Erwinia chrysanthemi (Sauvage et al. 1996). Here, we report that fegA is part of a two-gene operon involved in ferrichrome uptake. A $f e g A B$ mutant is unable to utilize ferrichrome as an iron source, suggesting that FegA is the outer membrane receptor for ferrichrome. A $f e g B$ mutant is also unable to utilize ferrichrome. FegB, a predicted inner membrane protein, does not have similarity to any characterized genes. As ferrichrome is produced by a variety of soil fungi, one might predict that FegA and FegB would play an important role in iron acquisition when $B$. japonicum is in the rhizosphere but that they would not be needed in planta. Surprisingly, the $f e g A B$ mutant also has a dramatic phenotype in planta. We discuss the possible roles of FegA and FegB in the soil and in planta.

\section{RESULTS}

Identification of a novel siderophore uptake operon.

Purification of iron-regulated OMP from $B$. japonicum $61 \mathrm{~A} 152$ allowed the cloning of the $f e g A$ gene (LeVier and Guerinot 1996). An open reading frame $(f e g B)$ was identified $52 \mathrm{bp}$ downstream of $f e g A$ (Fig.1). This open reading frame is 
not present in the $B$. japonicum USDA 110 genomic sequence. $f e g B$ is a gene of unknown function with several predicted homologs; none of these genes have been characterized. Interestingly, some of the $\mathrm{feg} B$ homologs, e.g., those found in Pseudomonas aeruginosa, $P$. fluorescens, Rhodopseudomonas palustris, and Caulobacter crescentus, are downstream of predicted TonB-dependent receptors that have homology with other ferrichrome receptors. The FegB protein is predicted to encode a 436-amino acid inner membrane protein containing eight transmembrane domains. In order to determine if the $f e g A$ and $f e g B$ genes are in an operon, primers were designed to the $3^{\prime}$ end of the $f e g A$ gene and the $5^{\prime}$ end of the $f e g B$ gene. Using RNA isolated from iron-starved $B$. japonicum cells, we were able to amplify the intergenic region using reverse transcriptase-polymerase chain reaction (RT-PCR), demonstrating that $f e g A$ and $f e g B$ are transcribed as a dicistronic message (data not shown). We also determined, using RT-PCR, that the $f e g A$ and $f e g B$ genes are not expressed under iron-sufficient conditions (data not shown).

\section{Construction and initial characterization of the $f e g A B$ mutant.}

In order to determine the type of siderophore transported via the FegA outer membrane receptor, the fegA gene was disrupted by inserting an omega $(\Omega)$ interposon cassette into the coding region and a recombinant strain carrying this mutation was obtained via triparental mating. Southern blotting was used to confirm that the chromosomal copy of fegA had been replaced by the interrupted version. RT-PCR was used to examine the expression of both $f e g A$ and $f e g B$ in the mutant strain. Neither gene was expressed, indicating that the insertion in $f e g A$ is polar on $f e g B$ (Fig. 2). Examination of the OMP profile via sodium dodecyl sulfate-polyacrylamide gel electrophoresis (SDS-PAGE) verified that the $f e g A B$ mutant no longer produced the FegA protein when cells were grown under iron-deficient conditions (Fig. 3, lanes 1 through 3).

Wild-type and $f e g A B$ cells were tested for their ability to utilize a variety of iron sources. Iron limitation was imposed by seeding bacteria into agar that contained the iron chelator ethylenediamine-di( $o$-hydroxy-phenylacetic acid) (EDDHA) at a concentration of $0.5 \mathrm{mM}$. In the presence of EDDHA, bacteria are unable to grow unless supplied with an iron source that can compete with EDDHA for iron binding. The wild-type strain was able to use all of the iron sources tested, including $\mathrm{Fe}(\mathrm{III})$ citrate, $\mathrm{Fe}$ (III) ferrichrome, $\mathrm{Fe}$ (III) desferal, hemin, and leghemoglobin (Fig. 4). The $f e g A B$ mutant strain was able to utilize all of the iron sources tested except for Fe(III) ferrichrome. The growth zone around the point source of $\mathrm{Fe}$ (III) ferrichrome was $2.2 \mathrm{~mm}$ for the $f e g A B$ mutant compared with $39.4 \mathrm{~mm}$ for the wild-type strain (Fig. 4). This result indicates that FegA is the ferrichrome receptor. Similar results were obtained when cells were cultured in yeast extract-mannitol
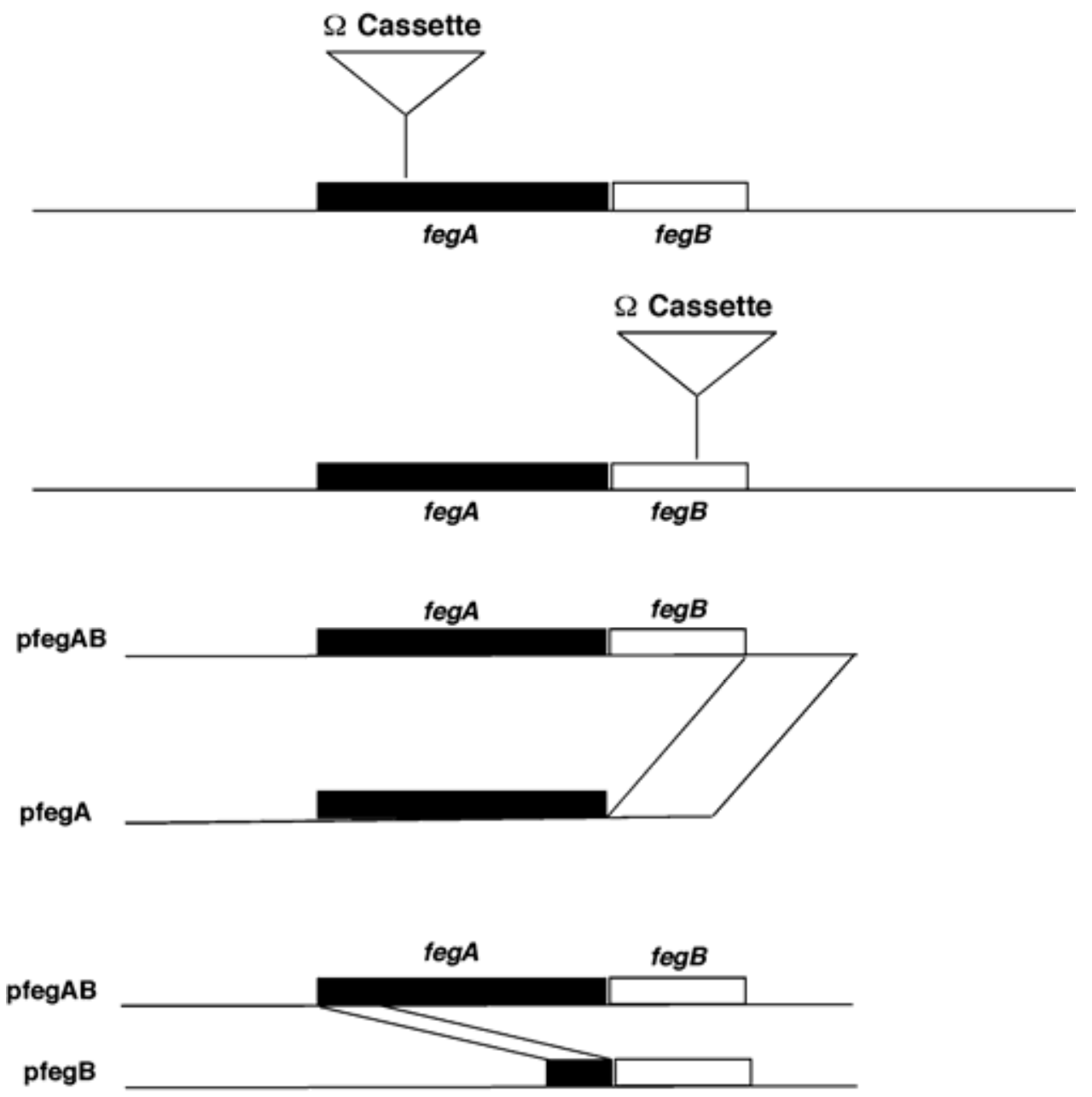

Fig. 1. Diagrams of the $f e g A B$ operon showing the location of the omega $(\Omega)$ cassette insertions carried by the $f e g A B$ and $f e g B$ mutants and the constructs used to complement these mutants. $f e g A$ and $f e g B$ are separated by only 52 nt. Downstream of $f e g B$ are the nuo genes. Upstream of $f e g A$ is an open reading frame predicted to encode a protein with homology to the MarR family of transcription factors. 
(YEM) liquid medium supplemented with $1 \mathrm{mM}$ EDDHA and were supplied with various iron sources (data not shown).

\section{Symbiotic phenotype of the $f e g A B$ mutant.}

The identification of FegA as a ferrichrome receptor suggested that FegA is likely to be important in the rhizosphere, in which ferrichrome would be readily available. We predicted that the $f e g A B$ mutant would probably be unimpaired in its ability to nodulate and to form an effective symbiosis. The $f e g A B$ mutant is indeed able to nodulate soybeans, but the nodules that form on plants inoculated with the $f e g A B$ mutant lack leghemoglobin; nodule heme content was $55 \mathrm{nmol}$ per gram of fresh nodule for plants inoculated with the wild type compared with undetectable levels for plants inoculated with the $f e g A B$ mutant. Nodules formed by the $f e g A B$ mutant have negligible rates of nitrogen fixation (Fig. 5). Plants inoculated with the
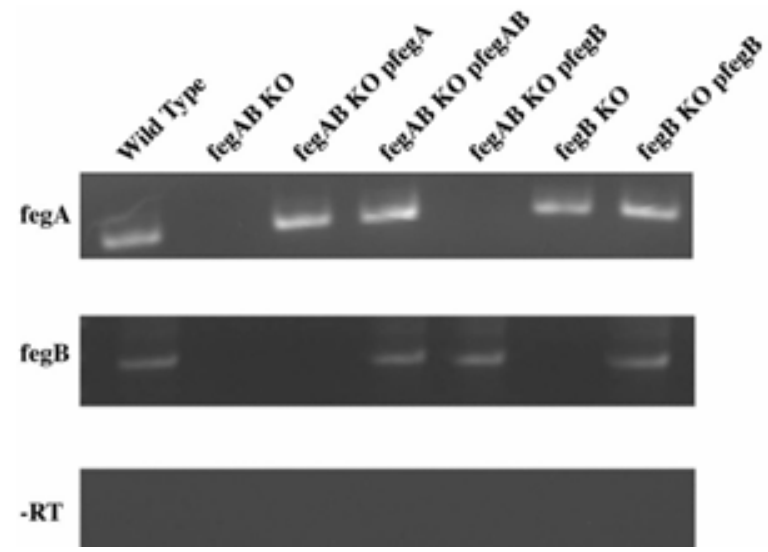

Fig. 2. Reverse transcriptase (RT)-polymerase chain reaction using total RNA isolated from iron starved cultures of Bradyrhizobium japonicum. $f e g A$ primers amplify a 321-bp band. $f e g B$ primers amplify a 369-bp band. Neither the $f e g A$ nor $f e g B$ primers amplified a band when the RT was omitted from the reaction. The results with $f e g A$ primers minus RT are shown.

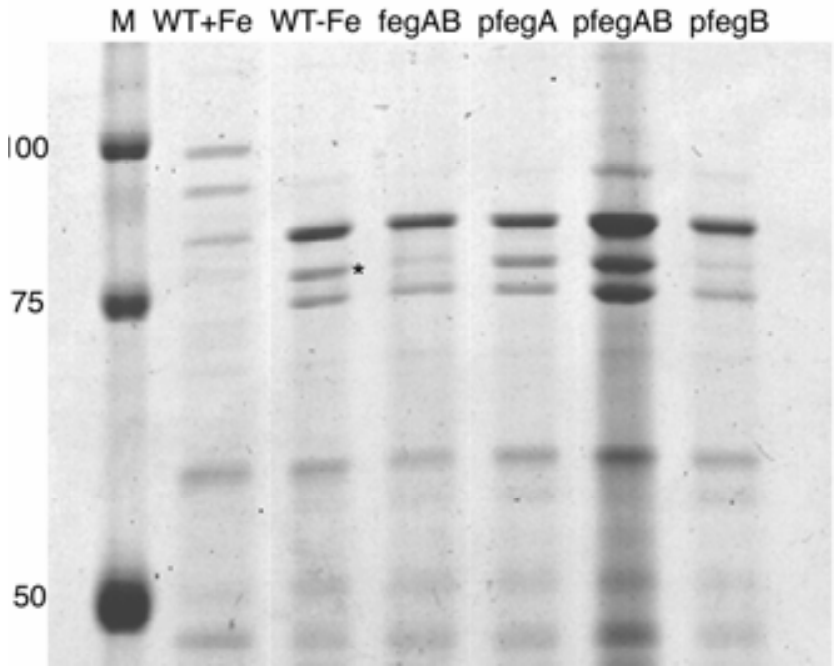

Fig. 3. Outer membrane proteins (OMP) prepared from Bradyrhizobium japonicum 61A152, the feg $A B$ mutant, and the three feg $A B$ transconjugant strains. Coomassie blue-stained sodium dodecyl sulfate-polyacrylamide gel electrophoresis of OMP prepared from cultures grown in the presence $(\mathrm{WT}+\mathrm{Fe})$ or in the absence of iron (WT-Fe, fegAB, pfegA, pfegAB, pfegB). Each lane was loaded with $75 \mu \mathrm{g}$ of protein in each lane. The FegA band is marked with an asterisk. Under iron-deficient growth conditions, the $f e g A B$ mutant did not express the FegA protein. The strains carrying $f e g A$ in trans express the FegA protein, while the strain carrying just $f e g B$ in trans does not express the FegA protein. $\mathrm{M}=$ molecular weight standards; sizes (in $\mathrm{kDa}$ ) are indicated on the left. feg $A B$ mutant also have more nodules than do plants inoculated with the wild-type strain (Fig. 5). These nodules are mostly present on lateral roots, whereas nodules induced by the wild-type strain are found mainly at the root crown. The total chlorophyll levels of plants inoculated with the $f e g A B$ mutant were significantly lower than levels from plants inoculated with wild-type bacteria (Fig. 5). Watering plants inoculated with the $f e g A B$ mutant with high iron solutions (50 and $500 \mathrm{mM}$ iron supplied as sequesterene) did not alter the symbiotic phenotype, suggesting the phenotype is not due to a lack of available iron. The $f e g A B$ mutant was also unable to form an effective symbiosis with an alternate host, cowpea (data not shown).

\section{Microscopy of nodules induced by the $f e g A B$ mutant.}

To better understand the phenotype of the $f e g A B$ mutant, we examined nodules at different times postinoculation (PI), via light and electron microscopy. At 3 weeks PI, nodules induced by the wild-type strain have a well-defined infection zone, located in the center of the nodule (Fig. 6B). In nodule primordia induced by the $f e g A B$ strain, several different zones of infection can be seen, none of which are as large or as well defined as those seen in nodules induced by the wild-type strain (Fig. 6A). Nodules induced by the wild-type strain have numerous infection threads, and infected cells contain many symbiosomes (Fig. 6D). In contrast, symbiosomes are nearly absent in cells of nodules induced by the $f e g A B$ mutant strain (Fig. 6C), although infection threads look similar to those seen in nodules induced by the wild-type strain. At 4 weeks PI, infected cells in plants inoculated with the $\operatorname{eg} A B$ mutant are significantly smaller than those found in nodules induced by wild type, with an average diameter of $35 \pm 2 \mu \mathrm{m}$ as compared with $50 \pm 2 \mu \mathrm{m}$, respectively. There is no difference in the size of uninfected cells (diameter of $19 \pm 3 \mu \mathrm{m}$ ) in nodules formed by wild type versus the $f e g A B$ mutant. At 6 weeks PI, infected cells in nodules formed by wild type are packed with symbiosomes, and each symbiosome contains one or two bacteroids (Fig. 6H). In contrast, cells infected with the mutant strain have few symbiosomes (Fig. 6G). Most strikingly, the infected cells are filled with vesicles of unknown origin (Fig. 6G).

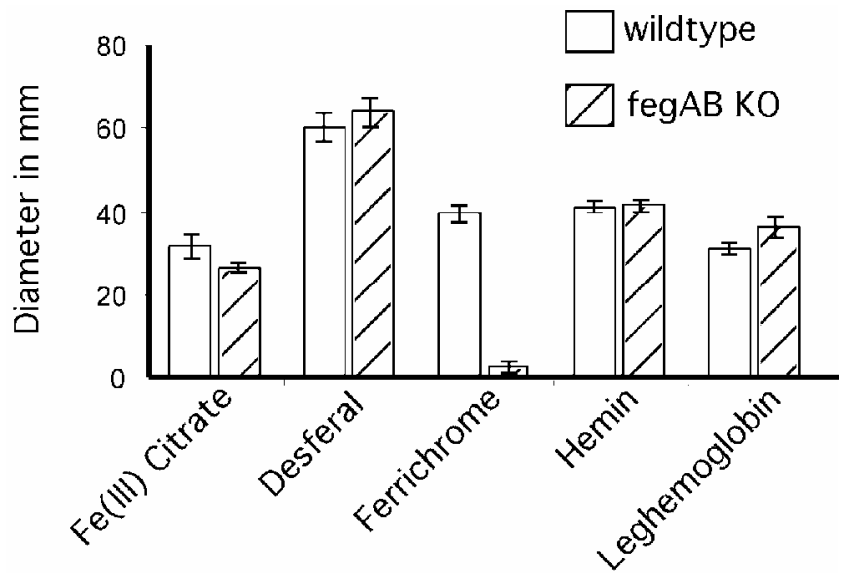

Fig. 4. Utilization of various iron sources by wild type (white bar) and the feg $A B$ mutant (hatched bar). Iron-starved cells were seeded into molten yeast extract-mannitol agar containing the iron chelator ethylenediamine di(o-hydroxy-phenylacetic acid) at a concentration of $0.5 \mathrm{mM}$. Under these conditions, there is no growth in the absence of a useable, exogenously supplied iron source. The diameter (in $\mathrm{mm}$ ) of the growth zone around each point-inoculated iron source was recorded 1 week after inoculation. All iron sources were provided at $25 \mathrm{nmol}$ except leghemoglobin, which was provided at $0.3 \mathrm{nmol}$. Results are an average of three to seven independent experiments (standard error is shown). 


\section{Characterization of the $f e g B$ mutant.}

By creating a $f e g B$ mutant, we hoped to determine if the phenotype of the $f e g A B$ mutant was the result of loss of function of the $f e g A$ gene or the $f e g B$ gene. The $f e g B$ gene was disrupted by inserting an $\Omega$ interposon cassette into the coding region of $f e g B$. A recombinant strain that carries this mutation was isolated via triparental mating. Southern blot analysis was used to confirm that a mutated copy of $f e g B$ replaced the chromosomal copy (data not shown). Figure 2 shows RTPCR analysis of $f e g A$ and $f e g B$ expression in the $f e g B$ mutant. $f e g B$ is not expressed in the mutant; however, $f e g A$ expression is unaltered.

$f e g B$ cells were tested for the ability to utilize ferrichrome. Using both siderophore plate assays (Fig. 7) and growth curve measurements, we determined that the $f e g B$ mutant is unable to grow when ferrichrome is the sole iron source provided. This indicates that, in addition to the FegA receptor, FegB is necessary for $B$. japonicum to utilize ferrichrome. The fegAB mutant has a very strong phenotype in planta. We wondered if the $f e g B$ mutant had a similar phenotype. Plants were harvested
Shoot Fresh Weight

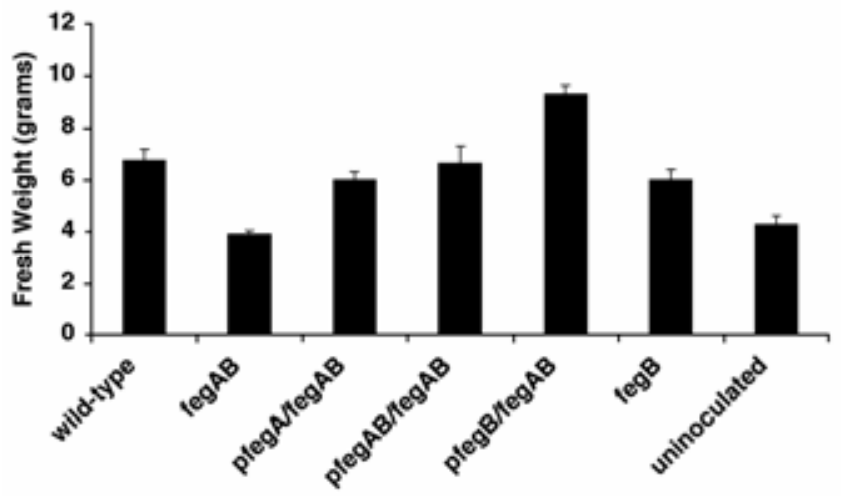

Nodules per Plant

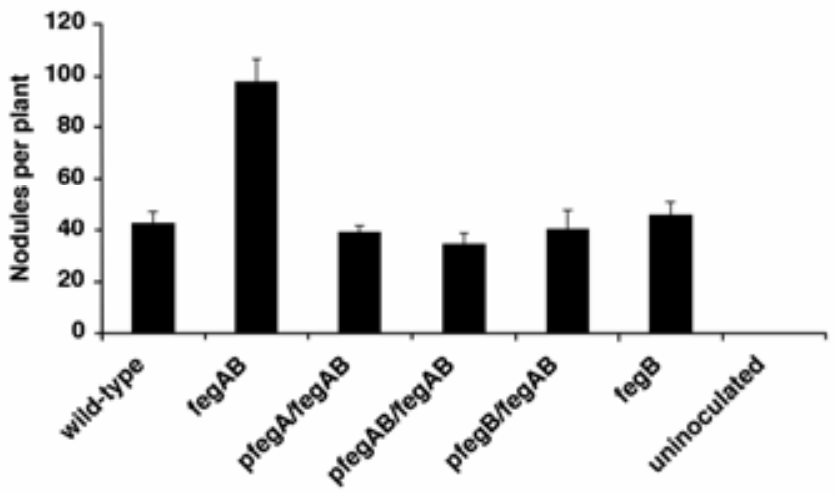

Chlorophyll Content

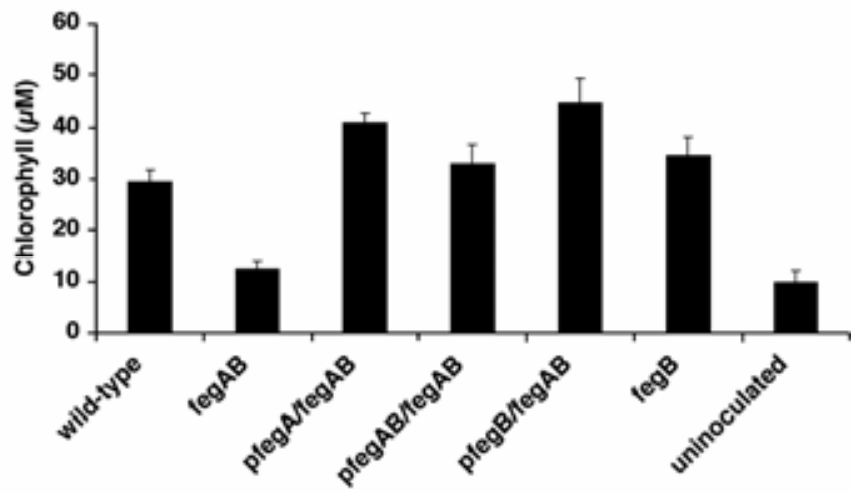

Acetylene Reduction

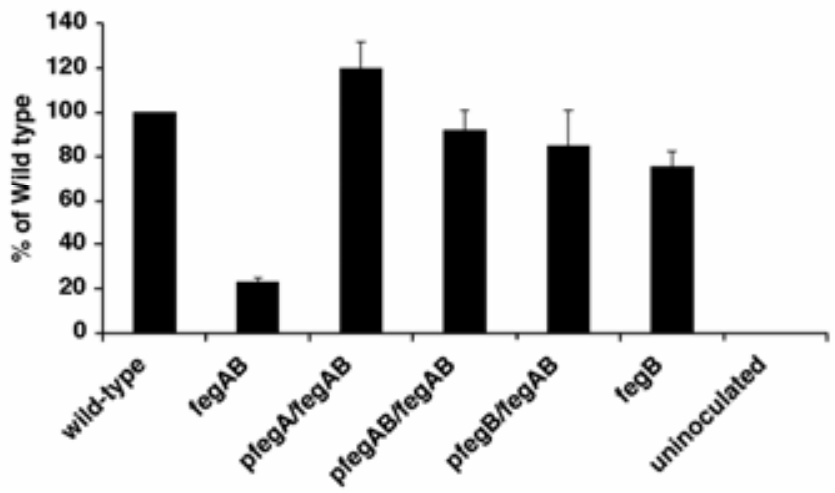

Heme Content

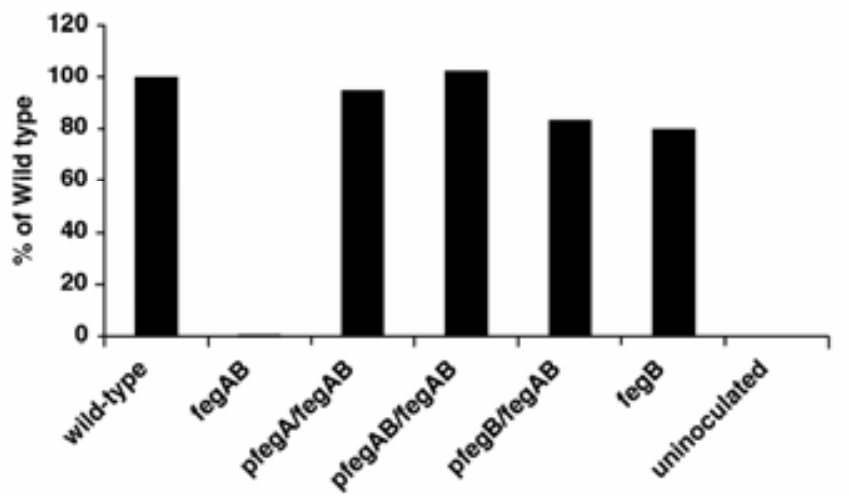

Fig. 5. In planta phenotypes of soybeans inoculated with Bradyrhizobium japonicum strains. Plants were harvested 28 days postinoculation and were assayed for average total chlorophyll content of the plant, average shoot fresh weight, average number of nodules per plant, nodule heme content, and nitrogen fixation activity as measured by the acetylene reduction assay. Nodule weights were also recorded (data not shown). Results represent the average of at least three independent trials (standard error is shown). 

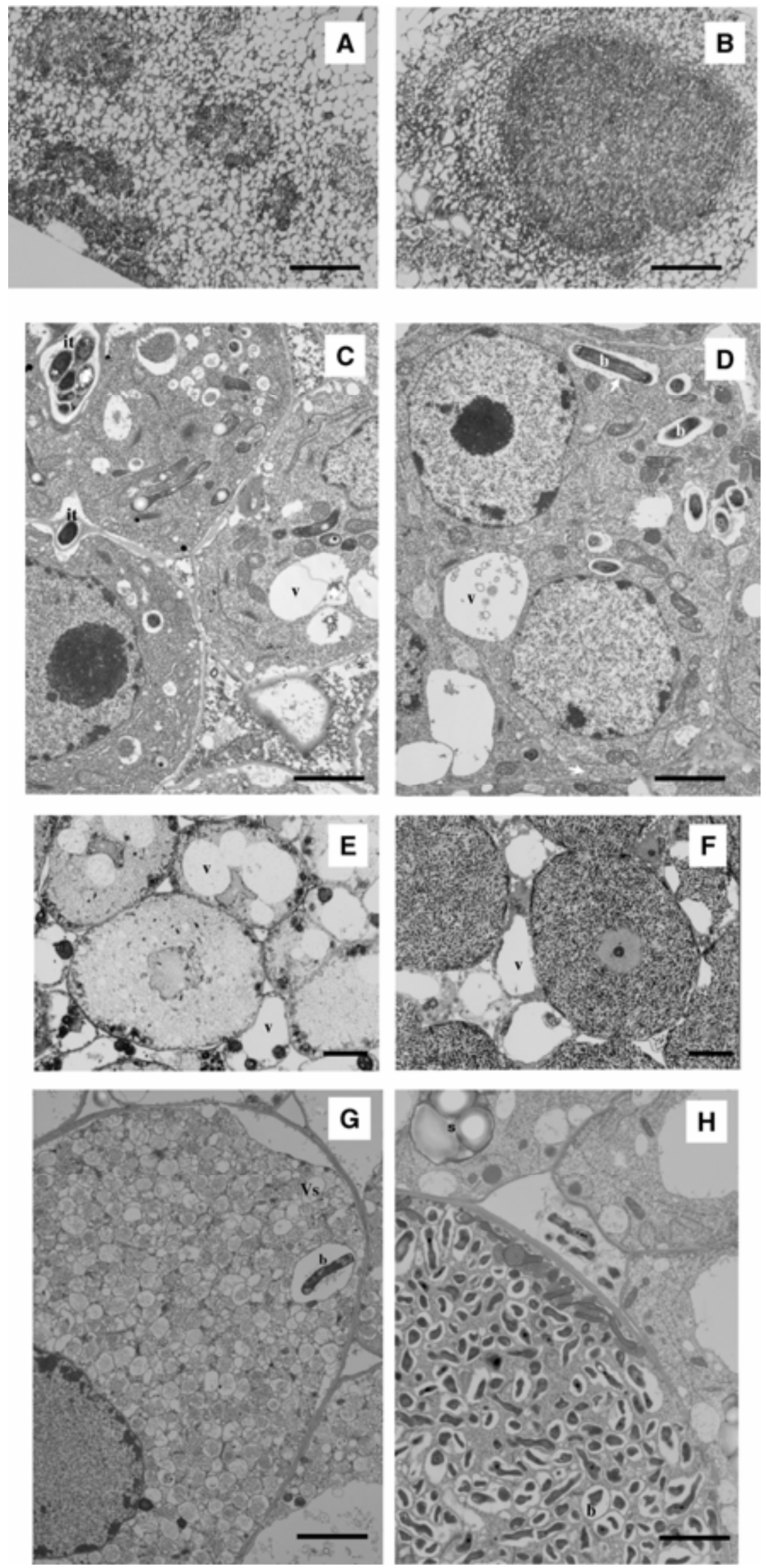

Fig. 6. Light and transmission electron micrographs of $\mathbf{A}, \mathbf{B}, \mathbf{C}$, and $\mathbf{D}, 3$-week-old and $\mathbf{E}, \mathbf{F}, \mathbf{G}$, and $\mathbf{H}$, 6-week-old soybean nodules induced by the fegAB mutant (A, C, E, and G) and wild type (B, D, F, and H). Scale bars: light microscopy, $100 \mu \mathrm{m}(\mathrm{A}$ and B) and $10 \mu \mathrm{m}(\mathrm{E}$ and $\mathrm{F})$; electron micrographs, $4 \mu \mathrm{m}(\mathrm{C}$ and $\mathrm{D})$ and $2 \mu \mathrm{m}(\mathrm{G}$ and $\mathrm{H}) . \mathrm{b}=$ bacteroid; it = infection thread; $\mathrm{s}=$ starch granule; $\mathrm{vs}=$ vesicle; $\mathrm{v}=$ vacuole. 
4 weeks after inoculation with either the $f e g B$ mutant or wildtype B. japonicum and were assayed for nitrogen fixation, heme content, number and weight of nodules, shoot fresh weight, and chlorophyll content. In all assays, the $f e g B$ mutant was indistinguishable from wild type (Fig. 5). The implication of these results is that FegA is required to form a functional symbiosis.

\section{Complementation of the $f e g A B$ and $f e g B$ mutants.}

Three low-copy plasmids carrying the entire $f e g A B$ operon or the operon with a deletion in either $f e g A$ or $f e g B$ were constructed (Fig. 1). All of these genes are expressed under the endogenous $f e g A B$ promoter. Via triparental matings, each of the three plasmids was moved into the $f e g A B$ mutant. The pfegB plasmid was also mated into the $f e g B$ mutant. RNA was prepared from each strain and was used in RT-PCR analysis. Figure 2 shows that all of the constructs are transcribed in $B$. japonicum. Expression of the iron-regulated OMP was also examined in each of the transconjugant strains (Fig. 3). The FegA protein is expressed in all strains carrying the $f e g A$ gene in trans.

All of the transconjugant strains were tested for ferrichrome utilization, using both the siderophore plate assay and growth curve measurements. Mutant analysis suggested that both FegA and FegB are required for ferrichrome uptake. The complementation analysis confirms these results. The only strains able to utilize ferrichrome are the wild-type strain, the $f e g A B$ mutant complemented with $f e g A B$ in trans, and the $f e g B$ mutant carrying $f e g B$ in trans (Fig. 7).

Each of the transconjugants was inoculated onto soybean to examine in planta phenotypes. As expected, expressing $f e g A B$ in trans complemented the $f e g A B$ mutant to wild-type levels (Fig. 5). This result also suggests that there is not a second mutation in the chromosome of the $f e g A B$ mutant that is responsible for the dramatic in planta phenotype. Based on the phenotype of the $f e g B$ mutant we anticipated that the $f e g A B$ mutant with $f e g A$ in trans would have a similar phenotype. Both of these strains form an effective symbiosis with soybeans (Fig. 5). We predicted the $f e g A B$ mutant with $f e g B$ in trans would be unable to form an effective symbiosis, the same phenotype as a nonpolar mutation in the fegA gene. Surprisingly, the expression of a construct carrying a truncated version of $f e g A$ and a complete copy of $f e g B$ restored the $f e g A B$ mutant to a wild-type symbiosis with soybeans (Fig. 5). This construct encodes 166 amino acids of the $\mathrm{N}$ terminus of FegA.

\section{DISCUSSION}

Wild-type B. japonicum 61A152 had previously been reported to utilize Fe(III) citrate (Guerinot et al. 1990) and $\mathrm{Fe}(\mathrm{III})$ ferrichrome (Plessner et al. 1993) as iron sources. Here, we add desferal, heme, and leghemoglobin to the list of iron sources that can be utilized by strain 61A152. Based on results with numerous other bacterial species, we expected FegA to serve as the outer membrane receptor for one or more of these iron sources. Although FegA did show the greatest amino acid similarity to outer membrane receptors for various hydroxamate siderophores, the identity of its ligand as the hydroxamate ferrichrome could only be determined by the construction of a mutant that no longer expressed the FegA protein.

In addition to identifying FegA as a receptor for ferrichrome, we have isolated a new operon associated with ferrichrome uptake. The B. japonicum ferrichrome uptake operon is very different from that found in E. coli. In E. coli, the ferrichrome uptake system is encoded by the fhuACDB operon. fhuA encodes the ferrichrome receptor, fhuC encodes an inner membrane-bound ATP-binding cassette protein (Burkhardt and Braun 1987; Coulton et al. 1987), FhuD is a periplasmic binding protein (Koster and Braun 1990), and FhuB is an integral inner membrane protein (Koster and Braun 1986). FhuBCD can interact with two other outer membrane receptors (FhuE, Iut) in addition to FhuA, demonstrating that transport across the cytoplasmic membrane is less specific than transport across the outer membrane. We have searched for homologs of $f h u B$, $f h u C$, and $f h u D$ in the complete genome sequence of $B$. japonicum USDA 110 (Kaneko et al. 2002a and b). fhuB and fhuC have homology with $B$. japonicum hmuU and $h m u V$, respectively, and the $h m u$ operon has been shown to be necessary for hemin and hemoglobin utilization (Nienaber et al. 2001). $\mathrm{HmuU}$ and HmuV may be specific for heme transport, as has been reported for other systems (Wandersman and Delepelaire 2004). There does not seem to be a homolog for fhuD in B. japonicum. Given that there are 10 presumptive outer membrane siderophore receptors predicted in B. japonicum, there is a noticeable lack of periplasmic and cytoplasmic membrane components predicted to be capable of partnering with these receptors. In $P$. aeruginosa, which is predicted to have 35 outer membrane receptors, the lack of periplasmic and cytoplasmic membrane transport components is even more pronounced, with only four potential $\mathrm{ABC}$ transporters. It has been suggested that $\mathrm{Fe}(\mathrm{III})$ siderophore complexes might be dissociated in the periplasm, allowing a single $\mathrm{Fe}(\mathrm{III})$ carrier to transport iron

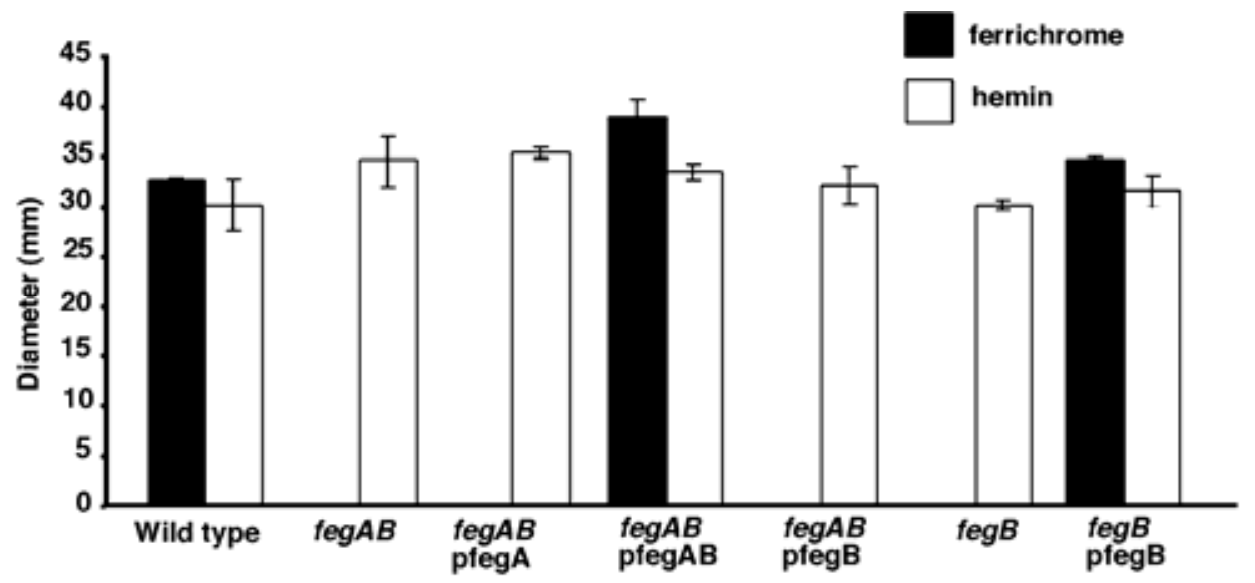

Fig. 7. Utilization of ferrichrome and hemin by Bradyrhizobium japonicum strains. Iron-starved cells were seeded into molten yeast extract-mannitol agar containing the iron chelator ethylenediamine-di(o-hydroxy-phenylacetic acid) at a concentration of $1 \mathrm{mM}$. Under these conditions, there is no growth in the absence of a useable, exogenously supplied iron source. The diameter (in $\mathrm{mm}$ ) of the growth zone around each point-inoculated iron source was recorded 7 days after inoculation. Iron sources were provided at $25 \mathrm{nmol}$. Results are an average of three to seven independent experiments (standard error is shown). 
into the cytoplasm from a variety of siderophores (Poole and McKay 2003).

The downstream gene in the $f e g$ operon, $f e g B$, has homologs in the GenBank database, all of which are uncharacterized. Interestingly, several of these genes are also located downstream of predicted TonB-dependent outer membrane receptors. By characterizing a $f e g B$ mutant in $B$. japonicum, we have shown that FegB is necessary for ferrichrome uptake. One might postulate that FegB has a function similar to FhuB or another inner membrane protein associated with the TonB complex. However, $f e g B$ has no sequence similarity with known inner membrane proteins that function with TonB-dependent receptors. In $S$. meliloti, there are also no predicted proteins with significant homology to the Fhu transport system apart from two orthologs of FhuA, one of which is the receptor for rhizobactin 1021 (RhtA). Cuív and associates (2004) have recently shown that the $S$. meliloti protein RhtX can substitute for FhuBCD to transport the $S$. meliloti siderophore rhizobactin in E. coli. Furthermore, introduction of $r h t X$ and $r h t A$ into a $S$. meliloti strain that cannot use rhizobactin 1021 was sufficient to confer the ability to use the siderophore. However, RhtX does not function in the transport of ferrichrome in either $S$. meliloti or E. coli, implying there must be another novel transport system for a hydroxamate siderophore in S. meliloti. The similarity between RhtX and FegB is low, but FegB could be acting in a manner similar to that of RhtX to facilitate transport across the inner membrane.

What are the implications for B. japonicum of being unable to utilize ferrichrome as an iron source? Because ferrichrome is synthesized by a variety of soil fungi, it is a likely iron source in the rhizosphere where hydroxamate concentrations have been estimated to be as high as $10 \mu \mathrm{M}$ (Crowley et al. 1987). Thus, a fegAB mutant might be at a disadvantage when competing against organisms that can utilize ferrichrome. But what is the explanation for the symbiotic defect of the fegAB mutant? For the $f e g A B$ mutant, nodulation is initiated but most bacteria fail to release from infection threads. There are other bacterial release (Bar-) mutants (ML126, ML150) of B. japonicum that appear to form nodules with defects similar to those formed by the fegAB mutant (Roth and Stacey1989b). That is, infected cells have few bacteroids and are filled with vesicles. Roth and Stacey (1989b) have suggested that the vesicles may arise from degradation of the infection thread cell walls. To date, the genes responsible for the Bar $^{-}$phenotype of these two mutants have not been identified.

We believe it is unlikely that the dramatic in planta phenotype of the $f e g A B$ mutant is due to the inability of the mutant to transport ferrichrome. We have not been able to measure the production of ferrichrome or any related hydroxamate compound when cells of $B$. japonicum $61 \mathrm{~A} 152$ are grown under iron-limiting conditions (Guerinot et al. 1990). Several rhizobial species have been shown to produce hydroxamates under culture conditions (Dilworth et al. 1998; Persmark et al. 1993), but there is no direct evidence that these siderophores are made in planta. In fact, mutants of $R$. leguminosarum that can no longer make or take up the hydroxamate they normally synthesize (vicibactin) are able to nodulate and fix nitrogen, suggesting that hydroxamate production is not important for this particular symbiosis (Stevens et al. 1999; Yeoman et al. 2000). Furthermore, the gene encoding the vicibactin receptor does not appear to be expressed in mature bacteroids, although GUS activity from a fhuA-gus fusion could be detected in the infection zone (Yeoman et al. 2000).

It is possible that the importance of FegA and FegB in planta has nothing to do with their role in iron uptake. Certain TonBdependent OMP contain an additional domain at their $\mathrm{N}$ terminus that is involved in signal transduction. This domain interacts with an inner membrane protein that, in turn, interacts with a sigma factor (Braun et al. 2003; Schalk et al. 2004). FegA is predicted to have an $\mathrm{N}$ terminal extension; similarity to FhuA, the E. coli ferrichrome receptor and other known ferrichrome receptors, only begins at residue 56 of the predicted mature FegA peptide. In Pseudomonas aeruginosa, the pyoverdine receptor that belongs to this class of receptors with $\mathrm{N}$ terminal extensions is involved in inducing genes necessary for iron uptake as well as other genes required for virulence (Beare et al. 2003; Lamont et al. 2002), providing a model for how FegAB might function in both iron uptake and in symbiosis. Although many members of the N-terminal extension subfamily of TonB-dependent receptors are involved in iron uptake, the Ralstonia solanacearum OMP that belongs to this class is involved in sensing the physical contact between this plant pathogen and plant cells, resulting in induction of the hypersensitive response (Brito et al. 2002). In the case of $R$. solanacearum, no ligand is believed to be transported. Likewise, in some of the iron uptake systems that belong to this class, it has been shown that transport of the ferric ligand is not necessary for the transcriptional induction of downstream genes (Schalk et al. 2004). It is possible that the rescue of the $f e g A B$ symbiotic phenotype, using the construct carrying a truncated version of FegA, may be due to expression of the FegA $\mathrm{N}$ terminus. It is also possible that overexpression of FegB might negate the need for FegA if FegB interacts with FegA as part of a signaling cascade. FegB is predicted to localize to the inner membrane and to have a leucine zipper-like motif; such a motif has been suggested to be important for interaction of the inner membrane class of proteins with the $\mathrm{N}$ terminal extensions of the OMP class (Braun et al. 2003).

Another explanation for the dramatic symbiotic phenotype of the $f e g A B$ mutant is that the FegA protein may be the receptor for some other compound whose uptake is critical to establish an effective symbiosis. There is certainly a precedent for OMP serving more than one function. In E. coli, the OMP FhuA serves as the receptor for ferrichrome, for the structurally related antibiotic albomycin and for the toxins colicin $\mathrm{M}$ and microcin 25 (Braun 1998). In addition, FhuA serves as a receptor for a variety of phages, including T1, T5, Ф80, and UC-1 (Braun 1998).

We have also isolated suppressors of the $f e g A B$ mutation in planta that may help elucidate the function of FegA and FegB. The suppressor strains maintain the omega cassette insertion in the $f e g A$ gene, and there is no expression of either $f e g A$ or $f e g B$. These stable suppressors are not able to utilize ferrichrome but are able to form an effective symbiosis with soybeans. These results further support the idea that $f e g A$ and $f e g B$ are not functioning to take up ferrichrome in planta. Characterization of the suppressor strains of the $f e g A B$ mutant may lead us to new genes involved in establishing a successful symbiosis.

\section{MATERIALS AND METHODS}

Bacterial strains, plasmids, enzymes, and chemicals.

Bacterial strains and plasmids used in this study are listed in Table 1. E. coli cultures were grown at $37^{\circ} \mathrm{C}$ in Luria-Bertani broth. B. japonicum cells were cultured at $30^{\circ} \mathrm{C}$ with shaking in either YEM medium or minimal medium supplemented with mannitol (Guerinot et al. 1990). Antibiotics were used when necessary at the following concentrations: with E. coli, ampicillin $(100 \mu \mathrm{g} / \mathrm{ml})$, kanamycin $(30 \mu \mathrm{g} / \mathrm{ml})$, tetracycline $(20$ $\mu \mathrm{g} / \mathrm{ml})$, spectinomycin $(100 \mu \mathrm{g} / \mathrm{ml})$ and streptomycin (100 $\mu \mathrm{g} / \mathrm{ml}$ ); with B. japonicum, kanamycin, spectinomycin, streptomycin, and tetracycline $(200 \mu \mathrm{g} / \mathrm{ml})$, and chloramphenicol or rifampicin $(30 \mu \mathrm{g} / \mathrm{ml})$. Desferal (deferoxamine mesylate salt), EDDHA, ferrichrome, hemin, and rhodotorulic acid were purchased from Sigma Chemical Co. (St. Louis). Nonidet P-40 
was from Calbiochem (La Jolla, CA, U.S.A.). Restriction enzymes and Klenow fragment of DNA polymerase were purchased from New England Biolabs (Beverly, MA, U.S.A.). Amplitaq DNA polymerase was from Perkin Elmer (Foster City, CA, U.S.A.). T4 DNA ligase and calf intestinal alkaline phosphatase were purchased from Gibco-BRL (Gaithersburg, MD, U.S.A.). All other chemicals were purchased from Sigma Chemical Co. unless otherwise stated.

\section{Plant assays.}

Glycine max soybean (Yellow butterbeans; Johnny's selected seeds, Albion, ME, U.S.A.) and cowpea (Pea Brown Crowder Miss Silver; Vermont Seed Co., Fair Haven, VT, U.S.A.) seeds were inoculated as previously described by Guerinot and Chelm (1986). Plants were grown in modified Leonard jars using $\mathrm{N}$-free medium. The shoots and roots were separated, and the fresh weight of the shoots was determined. Acetylene reduction assays were conducted as described by Guerinot and Chelm (1986). Chlorophyll extraction assays were performed using fresh leaf tissue. The protocol was adapted from Liscum and Hangarter (1991). Briefly, $0.1 \mathrm{~g}$ of fresh leaf tissue was collected, ethanol was added, and the tissue was ground, vortexed, and centrifuged. This extraction was repeated, the isolated supernatants were combined with ethanol and acetone, and the absorbance was measured at 664 and $647 \mathrm{~nm}$. Total chlorophyll was determined as described by Grann and Ort (1984). Strain verification of bacteria from nodules and heme quantification were conducted as previously described by Guerinot and Chelm (1986).

\section{Molecular techniques and $f e g A$ mutagenesis.}

All DNA manipulations were carried out according to standard procedures (Ausubel et al. 2005). The fegA mutagenesis was performed by insertion of a SmaI-digested $\Omega$ interposon cassette from pHP45- $\Omega$ into the NruI site of pBfegAEP (the NruI site is located 755 bases from the translational start site of $f e g A)$. Subsequently, the KpnI-XbaI fragment $(3.8 \mathrm{~kb})$ of this construct was subcloned into pRK415. Triparental mating was used to introduce plasmids from $E$. coli to $B$. japonicum (Ditta et al. 1980), using E. coli MT616 as a helper strain. The $\Omega$ insertion construct was recombined into the $B$. japonicum 61A152 genome, using the plasmid incompatibility technique with incompatible plasmid pPH1JI and selection for the $\Omega$ interposon cassette (Osteras et al. 1995).

In order to mutagenize $f e g B$, a 2-kb XhoI DNA fragment containing the entire $f e g B$ gene was cloned. A 370-bp segment of the coding region of $f e g B$ was removed by a $N a r I / N s i \mathrm{I}$ digest, and an $\Omega$ interposon cassette from pHP45- $\Omega$ was inserted into the coding region. This DNA fragment was cloned into pKC7 and was moved into B. japonicum via triparental mating with the pRK2013 helper plasmid.

The three complementation constructs used in this study were constructed in the broad-host-range plasmid pLAFR3. A 5.6-kb HindIII fragment containing the complete $f e g A B$ operon and promoter was cloned into the HindIII site of pLAFR3 in order to create pfegAB. pfegA was constructed by digesting the 5.6-kb HindIII fragment of the $f e g A B$ operon with EcoNI and $N s i \mathrm{I}$, in order to remove a $1.1-\mathrm{kb}$ fragment containing $f e g B$. pfegB was constructed by removing a $1.8-\mathrm{kb} S p h \mathrm{I} / E c o \mathrm{NI}$ fragment that contained most of the coding region of $f e g A$ from the original 5.6-kb $f e g A B$ DNA fragment.

\section{Isolation of OMP.}

OMP were prepared as previously described by LeVier and Guerinot (1996). Briefly, cells were ruptured using a French press, and OMP were purified using the nonionic detergent Nonidet P-40, which solubilizes the inner membrane, leaving the outer membrane intact, due to its low protein-to-lipid ratio (Bal and Shantharam 1980). Protein concentrations were estimated using the BCA assay (Pierce, Rockford, IL, U.S.A.). Proteins $(75 \mu \mathrm{g}$ per lane) were run on $7 \%$ SDS-PAGE gels in $1 \times$ Tris glycine buffer. Gels were Coomassie blue-stained, destained, and photographed. A prestained, protein molecular weight standard from BioRad was used.

Table 1. Bacterial strains and plasmids used in this study

\begin{tabular}{|c|c|c|}
\hline Strain or plasmid & Relevant characteristics & Source or reference \\
\hline \multicolumn{3}{|c|}{ Strains } \\
\hline \multicolumn{3}{|c|}{ Bradyrhizobium japonicum } \\
\hline $61 \mathrm{~A} 152$ & Nitrogen-fixing Glycine max symbiont & Nitragin Co., Milwaukee, WI, U.S.A. \\
\hline FegAB KO & $61 \mathrm{~A} 152$ fegA:: $\Omega$ insertion & This work \\
\hline FegB KO & $61 \mathrm{~A} 152$ feg $B:: \Omega$ insertion & This work \\
\hline \multicolumn{3}{|l|}{ Escherichia coli } \\
\hline DH5 $\alpha$ & 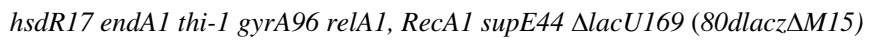 & Gibco-BRL, Gaithersburg, MD, U.S.A. \\
\hline Xl1-Blue & $\begin{array}{l}\text { Kan recAlendA1 gyrA96 thi-1 hsdR17 }\left(\mathrm{r}_{\mathrm{k}}{ }^{-} \mathrm{m}_{\mathrm{k}}{ }^{-}\right) \text {supE44 relA1 lac [ } \mathrm{F}^{\prime} \text { proAB } \\
\left.\text { lacI }{ }^{\mathrm{q}}{ }^{M} 15 \mathrm{Tn} 5\left(\mathrm{Km}^{\mathrm{r}}\right)\right]\end{array}$ & Stratagene, La Jolla, CA, U.S.A. \\
\hline MT616 & MT607(pRK600) & Finan et al. 1986 \\
\hline \multicolumn{3}{|l|}{ Plasmids } \\
\hline pRK2013 & $\mathrm{Km}^{\mathrm{r}}$ helper plasmid for mobilization & Figurski et al. 1979 \\
\hline pRK415 & pRK290 derivative with pUC9 polylinker, $\mathrm{Tc}^{\mathrm{r}}$ & Keen et al. 1988 \\
\hline pRK600 & ColE1 replicon with RK2 transfer region $\mathrm{Cm}^{\mathrm{r}}$ & Finan et al. 1986 \\
\hline pLAFR3 & pLAFR1 with pUC8 polylinker & Staskawicz et al. 1987 \\
\hline pBluescriptSK ${ }^{-}$ & Derivative of pUC19 with f1(-)oriR, $\mathrm{Ap}^{\mathrm{r}}$ & Stratagene \\
\hline pPH1JI & $\mathrm{IncP} \mathrm{Sp} \mathrm{r}^{\mathrm{r}} \mathrm{Gm}^{\mathrm{r}}, \mathrm{Cm}^{\mathrm{r}}$ & Hirsch et al. 1984 \\
\hline pHP45- $\Omega$ & $\mathrm{Ap}^{\mathrm{r}}, \mathrm{pBR} 322$ derivative with interposon $\Omega \mathrm{Sm}^{\mathrm{r}} / \mathrm{Sp}^{\mathrm{r}}$ & Prentiki and Krisch 1984 \\
\hline pBfegAEP & pBluescriptSK carrying B japonicum fegA 1.9-kb EcoRI/PstI fragment & This work \\
\hline pBfegAoN & pBluescriptSK carrying fegA $:: \Omega$ insertion & This work \\
\hline pRfegAoN & pRK415 carrying XbaI/KpnI fegA:: $\Omega$ cassette insertion & This work \\
\hline $\mathrm{pKC} 7$ & $\mathrm{Km}^{\mathrm{r}}$ ColE1 replication plasmid & Rao and Rogers 1979 \\
\hline pfegB $\Omega$ & pKC7 carrying $X h o$ I feg $B:: \Omega$ cassette insertion & This work \\
\hline pSfegAB & pBluescriptSK carrying $B$. japonicun feg $A B$ 5.6-kb HindIII fragment & This work \\
\hline pSfegA & pSfegAB with 1.1-kb EcoNI/NsiI fragment removed & This work \\
\hline pSfegB & pSfegAB with $1.8-\mathrm{kb} S p h \mathrm{I} / E c o \mathrm{NI}$ fragment removed & This work \\
\hline pfegAB & pLAFR 3 carrying 5.6-kb HindIII fegAB fragment from pSfegAB & This work \\
\hline pfegA & pLAFR 3 carrying $4.5-\mathrm{kb}$ HindIII fegA fragment from pSfegA & This work \\
\hline pfegB & pLAFR3 carrying 3.8-kb HindIII fegB fragment from pSfegB & This work \\
\hline
\end{tabular}

${ }^{\mathrm{a}} \mathrm{Cm}=$ chloramphenicol, $\mathrm{Gm}=$ gentamycin, $\mathrm{Km}=$ kanamycin, $\mathrm{Sm}=$ streptomycin, $\mathrm{Sp}=$ spectinomycin, and $\mathrm{Tc}=$ tetracycline. 
Light and electron microscopy.

Soybean nodules were removed from roots 3,4 , and 6 weeks PI, and $1-\mathrm{mm}^{3}$ pieces were cut from the center of each nodule using a razor blade. Nodules were fixed following the method described by Roth and Stacey (1989a). For light microscopy, $1 \mu \mathrm{m}$ thick sections were stained with toluidine blue and were photographed with a Zeiss Axioskope optical microscope. Thin sections (approximately $100 \mathrm{~nm}$ thick) were stained with uranyl acetate and lead citrate and were photographed with a JEOL 100CX electron microscope operating at $100 \mathrm{kV}$.

\section{Siderophore utilization assay.}

Cells were first starved for iron in minimal medium and then were seeded at a concentration of $10^{5} \mathrm{CFU} / \mathrm{ml}$ into molten YEM agar medium containing 0.5 or $1 \mathrm{mM}$ EDDHA (Noya et al. 1997). Neither wild type nor the mutants could grow under these conditions, due to the presence of the iron chelator EDDHA. After the agar had solidified, $5 \mu \mathrm{l}$ of $5 \mathrm{mM}$ iron stocks were added to toothpick holes made in the agar or were point-inoculated onto the surface of the plates. The diameter of the bacterial growth zone around the point source was measured after plates were incubated for 7 days at $30^{\circ} \mathrm{C}$.

\section{Isolation of total RNA and RT-PCR analysis.}

In order to isolate RNA from bacteroids, 4-week-old nodules were harvested and frozen in liquid nitrogen. Bacteroids were separated from the plant material as follows: $1 \mathrm{~g}$ of nodules was ground in liquid nitrogen and was resuspended in 3 $\mathrm{ml}$ of Tris-mannitol buffer (50 mM Tris, $500 \mathrm{mM}$ mannitol, $\mathrm{pH}$ 7.5). The samples were aliquoted into two microfuge tubes and were centrifuged for $5 \mathrm{~min}$ at $60 \times \mathrm{g}$ in a standard tabletop microfuge. The supernatant was removed and spun at $60 \times g$ for 5 $\min$ and then for $10 \mathrm{~min}$ at $10,000 \times g$. Total RNA was isolated from cultured B. japonicum and bacteroids, using the Qiagen RNeasy bacterial RNA isolation kit (Qiagen, Valencia, CA, U.S.A.). RNA was subsequently treated with RNase-free DNaseI (Gibco BRL). After DNase treatment RNA was phenol-extracted and ethanol-precipitated. Total RNA $(1 \mu \mathrm{g})$ was reverse-transcribed using M-MLV reverse transcriptase (Gibco BRL) with gene-specific primers. The resulting mRNA/cDNA heteroduplexes were treated with RNase $\mathrm{H}$ prior to PCR. Reaction products were heat-inactivated and frozen until further analysis. An aliquot $(1 \mu \mathrm{l})$ was utilized for PCR. PCR reaction conditions were 30 cycles $\left(94^{\circ} \mathrm{C}, 40 \mathrm{~s}, 58^{\circ} \mathrm{C}\left(\right.\right.$ fegA) or $62^{\circ} \mathrm{C}$ $(f e g B), 30 \mathrm{~s}, 72^{\circ} \mathrm{C}, 40 \mathrm{~s}$ ) with a 5-min final extension time at $72^{\circ} \mathrm{C}$. No amplification products could be detected when reactions were carried out in the absence of reverse transcriptase.

\section{ACKNOWLEDGMENTS}

We thank L. Howard for her expertise and technical support in carrying out light and electron microscopy. We thank A. Gray for help with the suppressor strains and J. Wang for help with the in planta assays. Critical reading of the manuscript and useful comments by $S$. Batchelet and $R$. McClung are warmly acknowledged. We are grateful to S. Moreau Marquis for the gift of leghemoglobin. This work was supported by United States Department of Agriculture grant 99-03686 to M. L. Guerinot. H. Benson was supported in part by an National Institute of Allergy and Infectious Diseases "Host-Microbe Interactions" training grant T32AI07519.

\section{LITERATURE CITED}

Andrews, S. C., Robinson, A. K., and Rodriguez-Quinones, F. 2003. Bacterial iron homeostasis. FEMS (Fed. Eur. Microbiol. Soc.) Microbiol. Rev. 27:215-237.

Ausubel, F. M., Brent, R., Kingston, R. E., Moore, D. D., Seidman J. G., Smith, J. A., and Struhl, K. 2005. Current Protocols in Molecular Biology. Greene Publishing Associates and John Wiley \& Sons, Inc. New York.

Bal, A. K., and Shantharam, S. 1980. Changes in the outer cell wall of
Rhizobium during development of root nodule symbiosis in soybean. Can. J. Microbiol. 26:1096-1103.

Beare, P., For, R., Martin, L., and Lamont, I. 2003. Siderophore-mediated cell signaling in Pseudomonas aeruginosa: Divergent regulate virulence factor production and siderophore receptor synthesis. Mol. Microbiol. 47:195-207.

Braun, V. 1998. Pumping iron through cell membranes. Science 282:22022203.

Braun, V., Mahren, S., and Ogierman, M. 2003. Regulation of FecI-type ECF sigma factor by transmembrane signaling. Curr. Opin. Microbiol 6:173-180.

Brito, B., Aldon, D., Barberis, P., Boucher, C., and Genin, S. 2002. A signal transfer system through three compartments transduces the plant cell contact dependent signal controlling Ralstonia hrp genes. Mol. Plant Microbe Interact. 15:109-119.

Burkhardt, R., and Braun, V. 1987. Nucleotide sequence of the $f h u C$ and $f h u D$ genes involved in iron (III) hydroxamate transport: Domains in FhuC homologous to ATP-binding proteins. Mol. Gen. Genet. 209:49-55.

Coulton, J. W., Mason, P., Cameron, D., Carmel, G., Jean, R., and Rode, H. 1986. Protein fusions of $\beta$-galactosidase to the ferrichrome-iron receptor of Escherichia coli K-12. J. Bacteriol. 165:181-192.

Coulton, J. W., Mason, P., and Allatt, D. 1987. fhuC and fhuD genes for Iron (III)-ferrichrome transport into Escherichia coli k-12. J. Bacteriol. 169:3844-3849.

Crowley, D. E., Reid, C. P. P., and Szaniszlo P. J. 1987. Microbial siderophores as iron sources for plants. Pages 375-386 in: Iron Transport in Microbes, Plants and Animals. G. Winklemann, D. van der Helm and J. B. Neilands, eds. VCH Publishers, New York.

Cuív, P. O., Clarke, P., Lynch, D., and O’Connell, M. 2004. Identification of $r h t X$ and $f p t X$, novel genes encoding proteins that show homology and function in the utilization of the siderophores rhizobactin 1021 by Sinorhizobium meliloti and pyochelin by Pseudomonas aeruginosa, respectively. J. Bacteriol. 186:2996-3005.

Dilworth, M., Carson, K., Giles, R., Byrne, L., and Glenn, A. 1998. Rhizobium leguminosarum bv. viciae produces a novel cyclic trihydroxamate siderophore, vicibactin. Microbiology 144:781-791.

Ditta, G., Stanfield, S., Corbin, D., and Helinski, D. 1980. Broad host range DNA cloning system for gram-negative bacteria: Construction of a gene bank of Rhizobium meliloti. Proc. Nat. Acad. Sci. U.S.A. 77:7347-7351.

Figurski, D. H., and Helinski, D. 1979. Replication of an origin-containing derivative of plasmid RK2 dependent on a plasmid function provided in trans. Proc. Natl. Acad. Sci. U.S.A. 76:1648-1652.

Finan, T., Kunkel, B., DeVos, G. F., and Signer, E. R. 1986. Second symbiotic megaplasmid in Rhizobium meliloti carrying exopolysaccharide and thiamine synthesis genes. J. Bacteriol. 167:66-72.

Grann, T., and Ort, D. 1984. Quantitation of the rapid electron donors to $\mathrm{P}_{700}$, the functional plastoquinone pool, and the ratio of the photosystems in spinach chloroplasts. J. Biol. Chem. 259:14003-14010.

Guerinot, M. L., and Chelm, B. K. 1986. Bacterial aminolevulinic acid synthase activity is not essential for leghemoglobin formation in the soybean/Bradyrhizobium japonicum symbiosis. Proc. Natl. Acad. Sci. U.S.A. 83:1837-1841.

Guerinot, M. L. Meidl, E. J., and Plessner, O. 1990. Citrate as a siderophore in Bradyrhizobium japonicum. J. Bacteriol. 172:3298-3303.

Guerinot, M. L., and Yi, Y. 1994. Iron: Nutritious, noxious and not readily available. Plant Physiol. 104:815-820.

Hirsch, P. R., and Beringer, J. E. 1984. A physical map of pPH1JI and pJB4JI. Plasmid 12:139-141.

Kaneko, T., Nakamura, Y., Sato, S., Minamisawa, K., Uchiumi, T., Sasamoto, S., Watanabe, A., Idesawa, K., Iriguchi, M., Kawashima, K. Kohara, M., Matsumoto, M., Shimpo, S., Tsuruoka, H., Wada, T., Yamada, M., and Tabata, S. 2002. Complete genomic sequence of nitrogen-fixing symbiotic bacterium Bradyrhizobium japonicum USDA110. DNA Res. 9:189-197.

Kaneko, T., Nakamura, Y., Sato, S., Minamisawa, K., Uchiumi, T., Sasamoto, S., Watanabe, A., Idesawa, K., Iriguchi, M., Kawashima, K., Kohara, M., Matsumoto, M., Shimpo, S., Tsuruoka, H., Wada, T., Yamada, M., and Tabata, S. 2002. Complete genomic sequence of nitrogen-fixing symbiotic bacterium Bradyrhizobium japonicum USDA110 (Supplement). DNA Res. 9:189-197.

Keen, N. T., Tamaki, S., Kobayashi, D., and Trollinger, D. 1988. Improved broad-host-range plasmids for DNA cloning in gram-negative bacteria. Gene 70:191-197.

Koster, W., and Braun, V. 1986. Iron hydroxymate transport of Escherichia coli: Nucleotide sequence of the $f h u B$ gene and identification of the protein. Mol. Gen. Genet. 204:435-442.

Koster, W., and Braun, V. 1990. Iron hydroxymate transport into Escherichia coli. Substrate binding to the periplasmic binding protein. J. Biol. Chem. 226:21407-21410. 
Lamont, I., Beare, P., Ochsner, U., Vasil, A., and Vasil, M. 2002. Siderophore-mediated signaling regulates virulence factor production in Pseudomonas aeruginosa. Proc. Natl. Acad. Sci. U.S.A. 99:7072-7077.

LeVier, K., and Guerinot, M.L. 1996. The Bradyrhizobium japonicum fegA gene encodes an iron-regulated outer membrane protein with similarity to hydroxamate-type siderophore receptors. J. Bacteriol. 178:72657275 .

Liscum, E., and Hangarter, R. P. 1991. Arabidopsis mutants lacking blue light-dependent inhibition of hypocotyl elongation. Plant Cell 3:685694.

Nienaber, A., Hennecke, H., and Fischer, H. M. 2001. Discovery of a haem uptake system in the soil bacterium Bradyrhizobium japonicum. Mol. Microbiol. 41:787-800.

Noya, F., Arias, A., and Fabiano, E. 1997. Heme compounds as iron sources for nonpathogenic Rhizobium bacteria. J. Bacteriol. 179:3076-3078.

Osteras, M., Stanley, M., and Finan, T. 1995. Identification of Rhizobiumspecific intergenic mosaic elements within an essential two-component regulatory system of Rhizobium species. J. Bacteriol. 177:5485-5494.

Persmark, M., Pittman, P., Buyer, J.S., Schwyn, B., Gill, P. R., and Neilands, J. B. 1993. Isolation and structure of rhizobactin 1021, siderophore from alfalfa symbiont Rhizobium meliloti 1021. J. Am. Chem. Soc. 115:3950-3956.

Plessner, O., Klapatch, T., and Guerinot, M. L. 1993. Siderophore utilization by Bradyrhizobium japonicum. Appl. Environ. Microbiol. 59:16881690 .

Poole, K., and MacKay, G. A. 2003. Iron acquisition and its control in Pseudomonas aeruginosa: Many roads led to Rome. Front. Biosci. 8:661-686.

Prentiki, P., and Krisch, H. M. 1984. In vitro insertional mutagenesis with a selectable DNA fragment. Gene 29:303-313.

Rao, R. N., and Rogers, S. G. 1979. Plasmid pKC7: A vector containing restriction endonuclease sites suitable for cloning DNA segments. Gene 7:79-82

Rogers, M., Sexton, J., DeCastro, G., and Calderwood, S. 2000. Identifica- tion of an operon required for ferrichrome iron utilization in Vibrio cholerae. J. Bacteriol. 182:2350-2353.

Roth, L. E., and Stacey, G. 1989a. Bacterium release into host cells of nitrogen-fixing soybean nodules: The symbiosome membrane comes from three sources. Eur. J. Cell Biol. 49:13-23.

Roth, L. E., and Stacey, G. 1989b. Cytoplasmic membrane systems involved in bacterium release into soybean nodule cells as studied with two Bradyrhizobium mutant strains. Eur. J. Cell Biol. 49:24-32.

Sangwan, I., and O'Brian, M. R. 1992. Characterization of $\delta$-aminolevulinic acid formation in soybean root nodules. Plant Physiol. 98:10741079

Sauvage, C., Franza, T., and Expert, D. 1996. Analysis of the Erwinia chrysanthemi ferrichrysobactin receptor gene: Resemblance to the Escherichia coli fepA-fes bidirectional promoter region and homology with hydroxamate receptors. J. Bacteriol. 178:1227-1231.

Schalk, I. J., Yue, W. W., and Buchanan S. K. 2004. Recognition of ironfree siderophores by TonB-dependent iron transporters. Mol. Microbiol. 54:14-22.

Staskawicz, B., Dalbeck, D., Keen, N., and Napoli, C. 1987. Molecular characterization of cloned avirulence genes from race 0 and race 1 of Pseudomonas syringae pv. glycinea. J. Bacteriol. 169:5789-5794.

Stevens, J., Carter, R., Hussain, H., Carson, K., Dilworth, M., and Johnston, A. 1999. The fhu genes of Rhizobium leguminosarum, specifying siderophore uptake proteins: fhuDCB are adjacent to a pseudogene version of fhuA. Microbiol. 145:593-601.

Verma, D. P. S., and Long, S. 1983. The molecular biology of Rhizobiumlegume symbiosis. Int. Rev. Cytol. Suppl. 14:211-245.

Wandersman, C., and Delepelaire, P. 2004. Bacterial iron sources: From siderophores to hemophores. Annu. Rev. Microbiol. 58:611-647.

Yeoman, K., Wisniewski-Dye, F., Timony, C., Stevens, J., deLuca, N., Downie, J. A., and Johnston, A. 2000. Analysis of the Rhizobium leguminosarum siderophore-uptake gene fhuA: Differential expression in free-living bacteria and nitrogen-fixing bacteroids and distribution of an fhuA pseudogene in different strains. Microbiol. 146:829-837. 